This item was submitted to Loughborough's Research Repository by the author.

Items in Figshare are protected by copyright, with all rights reserved, unless otherwise indicated.

\title{
Inspection methods for 3D concrete printing
}

PLEASE CITE THE PUBLISHED VERSION

https://doi.org/10.1007/978-3-030-49916-7_78

PUBLISHER

Springer

VERSION

AM (Accepted Manuscript)

PUBLISHER STATEMENT

This is a pre-copyedited version of a contribution published in Bos F., Lucas S., Wolfs R., Salet T. (eds) Second RILEM International Conference on Concrete and Digital Fabrication. DC 2020. The definitive authenticated version is available online via https://doi.org/10.1007/978-3-030-49916-7_78

\section{LICENCE}

CC BY-NC-ND 4.0

\section{REPOSITORY RECORD}

Buswell, Richard, Peter Kinnell, Jerry Xu, Norman Hack, Harald Kloft, Mehdi Maboudi, Markus Gerke, et al.. 2020. "Inspection Methods for 3D Concrete Printing". Loughborough University.

https://hdl.handle.net/2134/12233735.v1. 


\title{
Inspection methods for 3D Concrete Printing
}

\author{
Richard Buswell ${ }^{1}$, Peter Kinnell ${ }^{2}$, Jie Xu${ }^{1}$, Norman Hack $^{3}$, Harald Kloft ${ }^{3}$, Mehdi \\ Maboudi $^{4}$, Markus Gerke ${ }^{4}$, Peter Massin ${ }^{5}$, Georg Grasser ${ }^{5}$, Rob Wolfs ${ }^{6}$, Freek Bos ${ }^{6}$ \\ ${ }^{1}$ School of Architecture, Building and Civil Engineering, Loughborough University, UK \\ ${ }^{2}$ Wolfson School of Mechanical, Electrical and Manufacturing Engineering, Loughborough \\ University, UK \\ ${ }^{3}$ Institute of Structural Design, Technische Universität Braunschweig, Germany \\ ${ }^{4}$ Institute of Geodesy and Photogrammetry, Technische Universität \\ Braunschweig, Germany \\ ${ }^{5}$ Institute for Experimental Architecture, Universität Innsbruck, Austria \\ ${ }^{6}$ Department of the Built Environment, Eindhoven University of Technology, Netherlands
}

R.A.Buswell@lboro.ac.uk

\begin{abstract}
D Concrete Printing (3DCP) is being used for off-site manufacture of many elements found in the built environment, ranging from furniture to bridges. The advantage of these methods is the value added through greater geometrical freedom because a mould is not needed to create the form. In recent years, research has focused on material properties both in the wet and hardened state, while less attention has been paid to verifying printed forms through geometry measurement. Checking conformity is a critical aspect of manufacturing quality control, particularly when assembling many components, or when integrating/interfacing parts into/with existing construction. This paper takes a case study approach to explore applications of digital measurement systems prior to, during, after manufacture using 3DCP and after the assembly of a set of 3DCP parts and discusses the future prospects for such technology as part of geometry quality control for the procurement of 3DCP elements for the built environment.
\end{abstract}

Keywords: 3D Concrete Printing; Geometric inspection; Quality control; Additive manufacturing

\section{Introduction}

The construction industry has been slower than other industries to adopt automation and digitalization in its manufacturing [1,2]. This remains the case and the current drive for 'Industry 4.0' standards promote the adoption of automation in manufacturing $[3,4]$. As a result, many Digital Fabrication processes that form Concrete (DFC) are emerging, with additive methods being the most common [5]. Many demonstrators on the building scale have been realised, and the science behind the materials continue to be investigated [6-9]. 
There has been less exploration of the geometric conformity of manufactured parts. Early work that recognised printing resolution issues for 3DCP was presented by Buswell et al. [10], and Buswell et al. [11], with examples of error measurement using photogrammetry in Lim et al. [12]. More recent research has been presented by Xu et al. [13] in real-time varying the bead size to reduce geometric errors, and by Ketel et al. [14] in developing a printability index to link mortar rheology to the geometrical attributes.

Quality inspection is an essential part of quality control [15], based on drawings and specifications detailing the requirements for materials and workmanship, mostly fulfilled via idiographic field testing in casting concrete products $[16,17]$. The quality required for reliable assembly of several parts becomes more challenging [18] and in manufacturing, such geometric inspection is often performed on a batch of products using statistical measures [19].

Inspection through digital geometric measurement has become common in construction and manufacturing [20-22], and will play an increasingly significant role, due to the fact that $3 \mathrm{D}$ printed components tend to be geometrically more complex and are hence difficult to measure with traditional means. There are different approaches for reality capture that can be applied in 3DCP, which depend on component scales, shape complexity, construction stages, ambient environmental conditions and other technical or economic demands. Classic approaches like using a Total-station are applicable just for simple components. However, 3D laser scanning and photogrammetry-based approach also including structured light-based methods are expressed as the most dominant data capturing approaches $[23,24]$.

In order for Additive Manufacturing (AM) to find its way into the construction industry in the long term, geometric conformity of 3DCP components to the planned model and specified tolerances of the final products will need to be quantified efficiently using the aforementioned inspection techniques. This applies both to in-situ printed structures on which further building elements, as well as to prefabricated elements that are assembled at the construction site. This paper explores applications of digital geometric inspection methods applied to four stages of the manufacturing and assembly process using 3DCP:

- determining process capability prior to manufacture;

- adaptive fabrication during production;

- evaluating of form for postprocessing; and,

- building documentation after assembly. 


\section{Background}

\subsection{Additive Manufacture with Concrete}

There are two approaches that utilise the placement of premixed cement-based mortar in a layerwise under digital control. Extrusion-based 3D concrete printing (3DCP) [25] is similar to the Fused Deposition Modelling (FDM), where fine grain concrete is extruded in filaments and deposited in a layer superposition manner to reach the target geometry [26,27]. Fig. 1 a, b and d present examples. Fig. 1c presents a material jetting process based on the principles of shotcrete [28] to deposit the material in a similar single nozzle toolpath approach. Both techniques are reported in the case studies presented, although the methods discussed apply to many other processes.

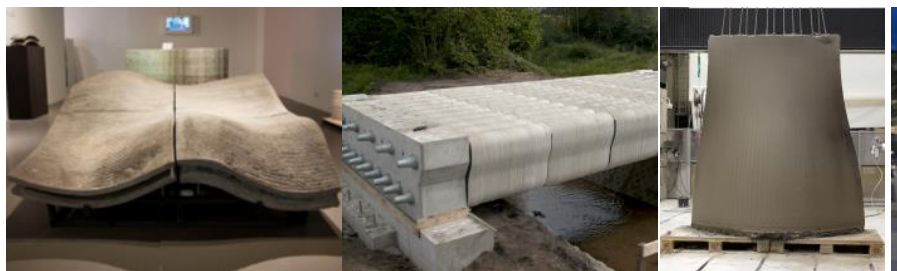

(a) (b)

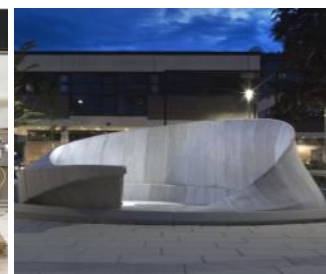

(d)

Fig. 1. Typical 3DCP demonstrations: (a) doubly-curved panel (Loughborough University); (b) pedestrian bridge (TU Eindhoven); (c) doubly-curved reinforced wall (TU Braunschweig); (d) COHESION pavilion (University of Innsbruck).

\subsection{Geometric inspection methods and tools applied in 3DCP}

Data acquisition. The data acquisition methods can be affected by parameters like geometric deviations, visualization capabilities, the level of the inspector's experience, and degree of automation [29]. A systematic study and review on this is presented by Kim et al. [24].

3D laser scanning. 3D laser scanning and especially Terrestrial Laser Scanning (TLS) has become a common technology to acquire accurate $3 \mathrm{D}$ point clouds ${ }^{1}$ in many engineering fields. High accuracy, ability to measure long ranges and low dependency on usual atmospheric conditions (lighting in particular) are the main advantages. However, material reflectivity, high cost, level of detail (LOD) dependency on the distance to the object, low portability and operational difficulties in congested areas and possible noise due to moving machinery and personnel in the construction site are limitations [30]. Typical applications of using laser scanned as-built data of components and structures for geometrically dimensional inspection (in comparison to design CAD

\footnotetext{
${ }^{1}$ The point cloud is a term used for a set of unordered points, which are spatially sampling an object.
} 
models) can be found in Akinci et al.[31], Gordon et al. [32], Bosche [33], and Kim [34].

Photogrammetry. The availability of inexpensive digital cameras has significantly increased the number of photos that are being captured on construction sites on a daily basis [35]. Photogrammetric techniques have an advantage that the sampling is more continuous than laser scanning, although the pixel size is a limiting factor. Challenges of this approach include: the sensitivity to different lighting conditions, especially regarding severe shadow and low textured surfaces and windows; occlusion: capturing at each standpoint is limited to the closest structural part of the component to the camera; and each component must be visible from multiple (at least two) different points of view and those need to resemble a good image ray intersection geometry. Examples of use in construction include observations using unmanned aerial vehicles (UAV) both outside [36] and inside buildings [37].

Structured light scanning. Structured light scanning has been one of the most widely applied optical 3D measurement techniques because of its ease of implementation and fast full-field measurement. Structured light scanners work by projecting a patterned field of light, usually a set of sinusoidal stripes, onto the surface being measured. The set of projected light patterns is then captured using a camera and combined to allow the projected field of light to be unambiguously defined. This allows a process of triangulation to be used to determine the spatial position of imaged pixels to represent points on the imaged surface, creating a point cloud. Short scanning time, high resolution and highly-reduced dependency on material, texture and lighting conditions are the key benefits of this approach. However, this technology only works on relatively small objects located close to the projector.

Coregistration. Often it is desirable to compare the printed object with the digital model and so registration of the measurements with the 3D model must be undertaken often with methods like ICP [38]. Although this approach works in many cases comparing two solid objects, its results could contain bias especially in AM products while ICP tries to minimize the difference between the two entities. Other approaches are to register point clouds and the physical object based on clearly defined targets. Some other researchers used a so-called feature based coregistration for this purpose [34].

\section{Case studies}

The following case studies demonstrate inspection at four stages of manufacture and assembly: pre-printing for process and material evaluation, during printing to compensate for plastic deformation, after printing for application of secondary processes, and post assembly for 'As Built' records. 


\subsection{Determining process capability: prior to printing}

The evaluation of process capability in terms of the manufacturing precision is needed to inform the design of the part and as a benchmark for improvement, or system verification checking. Here a 'standard' test geometry was manufactured using an extrusion based 3DCP process (Further details in [39]). Positioning of the nozzle was via an $A B B$ industrial robot and material was supplied via a worm pump. Several parts were printed using varying nozzle sizes $(8 \mathrm{~mm}, 12 \mathrm{~mm}$ and $16 \mathrm{~mm})$, where the layer height was parametrically linked by a ratio of 0.52 , giving respective layer heights of $4.2 \mathrm{~mm}, 6.3 \mathrm{~mm}$ and $8.3 \mathrm{~mm}$. Three parts were manufactured for each diameter using the same hatching pattern and step were taken to minimise the impact of mortar rheology, generating an inspection lot. Each part was then scanned using a DAVID SLS-3 structured light scanner for cost effectiveness and reasonable precision. The scanner performed several scans from different directions to capture the whole part geometry (Fig. 2a). Each scan was then processed (denoising, background removal and ICP registration) using CloudCompare [40] to obtain the complete point cloud. This systematic approach can be adapted to isolate influences that might affect the final geometry in a systematic test.

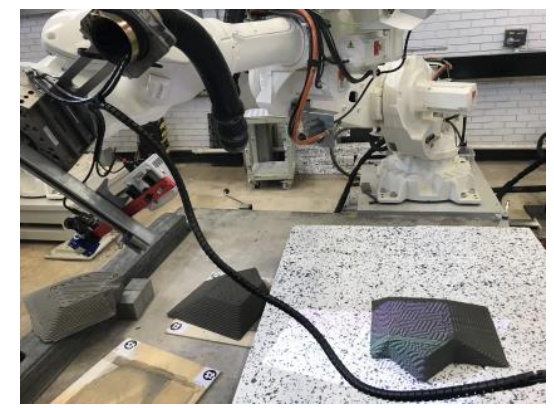

(a)

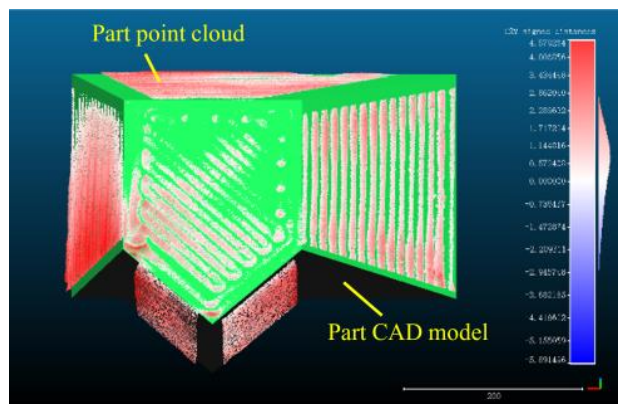

(b)

Fig. 2. Structured light-based geometric inspection: (a) data acquisition; (b) flat face profile deviation measurement.

The six flat faces were inspected for flatness and profile errors. For each area, the deviation between each point in the point cloud and the surface of the CAD model was measured (Fig. 2b). The inspected errors allowed the feature tolerances to be evaluated and plotting the data against anticipated effects can help identify unexpected influences. For example, Fig. 3 shows the maximum positive deviation errors as a function of nozzle diameter, for each of the inclined and vertical planes on the part. The wellknown 'staircase effect' [41] might be expected to dominate and present a linear relationship. The impact of the consistency in the material, even with care, leads to a lack of correlation. The diagrams also demonstrate that the error tends to reduce as the inclination increases because the layer height exacerbates the approximation errors to the flat surface. These insights might then be reasonably applied as constraints in the 
design of a component, as a benchmark against which improvement strategies can be measured.

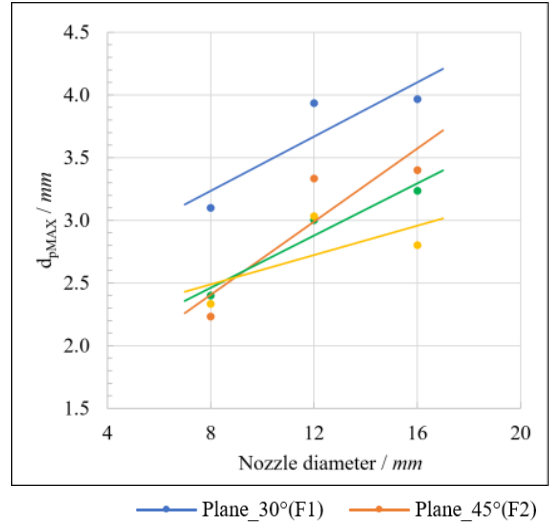

(a)

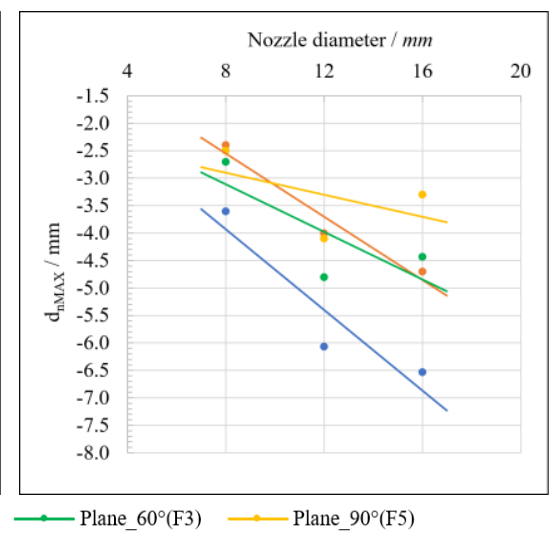

(b)

Fig. 3. Flatness errors variation of flat faces along with the nozzle diameter for different inclined angles: (a) maximum positive deviation; (b) maximum negative deviation.

\subsection{Adaptive feedback: during printing}

During printing, parameters may be controlled or anticipated a-priori. Others may fluctuate during a printing process, or between printing sessions: environmental conditions or geometric deviations due to cumulative deformations in layers of freshly deposited material for example. Even the exact geometrical properties of the 'print-bed' may be unknown. In such cases, the process conditions deviate from expected, which in turn leads to errors or possibly print failure. To avoid this, one approach is using realtime measurement and adaptive feedback.

Wolfs et al. [42] developed a system to perform continuous adjustment of the nozzle height during printing. A 1D Time of Flight (ToF) distance sensor, with an accuracy of approx. $1 \mathrm{~mm}$ and a range up to $200 \mathrm{~mm}$, attached to the nozzle of the 3D printer. The sensor was positioned directly in front of the nozzle and could react instantly to the measurements via a wireless motion controller. Here, the data is collected, and continuously compared to a predefined, desired nozzle height. When deviations occur, a PID (proportional-integral-derivative) feedback system overrules the prescribed 3D print instructions (G-Code) and corrects the nozzle position in real-time.

The adaptive feedback system was demonstrated in a $250 \mathrm{~mm}$ radius cylinder wall printing. When the wall was printed with a conventional fixed increment in the z-height (Fig. 4a), deformations resulted in a significant deviation of the nozzle height, leading to poor layer placement and finally collapse. Using the feedback system ensured consisted nozzle position with respect to the working surface and a successful print of 50 layers (Fig. 4b). 


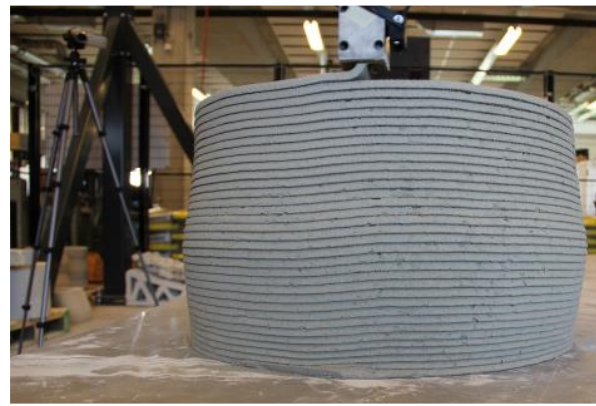

(a)

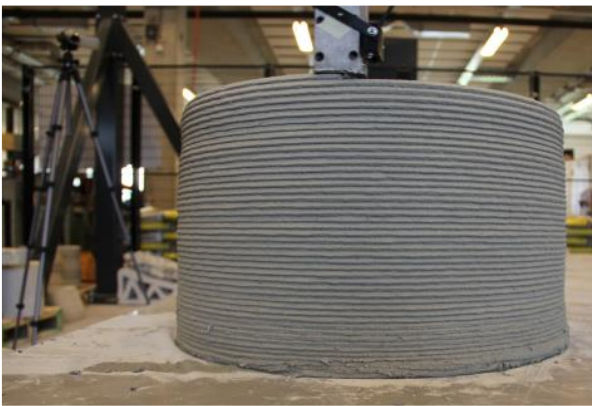

(b)

Fig. 4. 3D printed cylinder walls without (a) and with (b) the adaptive feedback system (figures reproduced from [42]).

\subsection{Postprocessing operations: in between to production steps}

AM often results in undesirable level of precision in the surface finish and postprocessing is required to bring the part into tolerance. Here the SC3DP technique [43] was applied to manufacture a doubly-curved, fully-reinforced concrete wall of $2.5 \times$ $0.18 \times 2.3 \mathrm{~m}$ including manual placement of pre-bent horizontal and vertical reinforcement (Fig. 5). The first stage was to print the vertical wall, install reinforcement, and then to spray the vertical surface, prior to a troweling operation to smooth the surface. The initial print was $3 \mathrm{D}$ scanned so that the as-printed part could be used to generate the tool path for the second spray process.

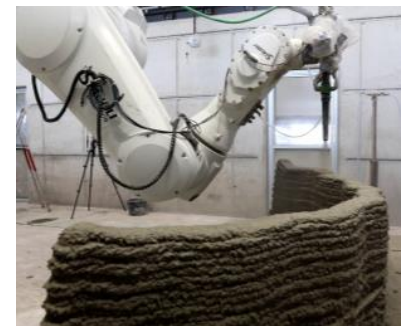

(a)

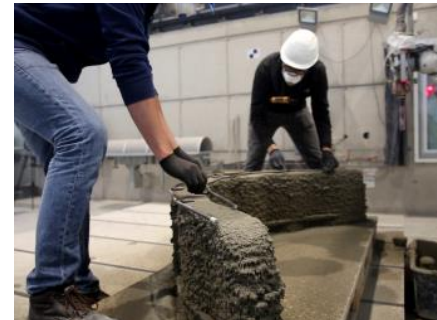

(b)

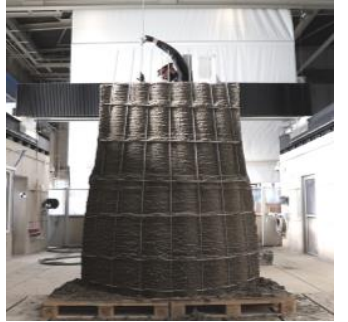

(c)

Fig. 5. SC3DP with reinforcement: (a) wall shotcrete 3D printing; (b) manual placement of the pre-bent horizontal bars; (c) threading in the vertical bars.

3D laser scanning and multi-view photogrammetry were used to generate 3D point clouds of the printed components. Data was acquired under different object conditions (dry/wet, with/without reinforcement, before/after surface finishing) in order to take possible conditions on real construction projects into account. Fig. 6 depicts as-planned model of the demonstrator and data capturing in different steps using above mentioned techniques. For multi-view geometry a non-professional digital camera was used and 80 images were captured. Then, PiX4D software was used to align the images and find 
the key points and perform the image matching. For 3D laser scanning, Leica P20 TLS was used to scan the object from 6 stations ( 2 stations before reinforcement and 4 stations on final product) with the average distance of 3 meters between the scanner and the object. The average density of the point clouds is less than $2 \mathrm{~mm}$. Considering localization of the instrument in each station, it takes ten minutes to run a scan on each station. As 3D laser scanning is a direct measurement of the points, no special postprocessing is required.

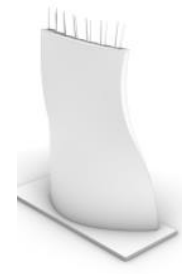

(a)

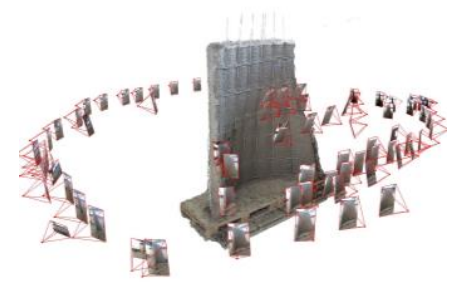

(b)

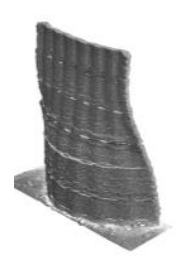

(c)

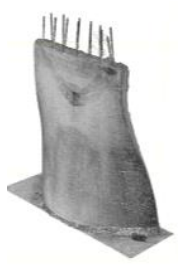

(d)

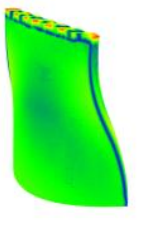

(e)

Fig. 6. Geometric inspection of a component: (a) 3D designed model of the wall; (b) photogrammetric block around the fabricated wall; (c) TLS data before reinforcement; (d) TLS data after reinforcement; (e) wall model colourised by $\mathrm{C} 2 \mathrm{C}$ distance.

Eight targets were installed on different parts of the printing environment (cf. 2.2 coregistration) and their coordinates were also measured using the robotic arm in order to co-register the designed 3D model and the point cloud data acquired from the printed entity. TLS and photogrammetric point clouds as well as a 3D model were then coregistered using the $3 \mathrm{D}$ similarity transformation. Cloud to cloud $(\mathrm{C} 2 \mathrm{C})$ and cloud to mesh $(\mathrm{C} 2 \mathrm{M})$ distances were utilised to measure the deviations of the printed component from its digital twins.

\subsection{Assembly verification: after installation}

The COHESION pavilion at the University of Innsbruck (Fig. 1d, [44]) comprised of 47 unique components that were assembled into the installation of $6.20 \mathrm{~m}$ diameter, $2.70 \mathrm{~m}$ height and 12.2 tons of weight. Every layer in each part of the assembly constantly changed in height between 4.50 and $12.00 \mathrm{~mm}$, generating material deposition issues. The challenge here was to verify that the whole assembly was within tolerance using two parallel options for larger-scale measurement: photogrammetry and 3D laser scanning.

For photogrammetry, a drone set-up with a DJI Phantom 4 Plus, $4 \mathrm{~K}$ sensor and predefined flight paths as well as Agisoft's Meta Shape for calculations was used. This produced 136 images in 1 hour of flight and took approx. 3 days of calculation with 16point cloud fragments, containing 13,304,966 points in total.

The 3D laser scanning with a Faro Focus S150 took approx. 1 hour for 8 scans, which yielded varying numbers of points from 468,436 - 12,653,468 in each point cloud, 
containing 23,924,383 points in total. The different amount of points in the individual scans was caused as some of the scans covered smaller areas on the pavilion exterior; the bigger ones covered more extensive areas (e.g. the interior). The surface area of the outer shell is approx. $88 \mathrm{~m}^{2}$, resulting in a density of approx. $27 \mathrm{pts} / \mathrm{cm}^{2}$ in the merged point cloud.

Once the orientationally adapted CAD model and the data sets from the two measurement approaches was aligned (Fig. 7a), a detailed data comparison (of 565 points) was achieved by measuring the distances between the CAD model and the scans. The precision of the photogrammetric data was reasonable for the general orientation and the build design evaluation, whilst the laser scanning was far more precise. A limit of $12 \mathrm{~mm}$ of deviation was defined to cull out problems of the closest point comparison. In the photogrammetric model, more than half of the points showed deviations above the limit (Fig. 7b). 110 points with more than $12 \mathrm{~mm}$ deviations (Fig. 7c) from laser scanning had to be visually checked, where 24 points actually had a deviation and others were at the boundary conditions of the structure which led to closest point comparison problems. 16 of the 24 points were located at the top-crease of the pavilion, which was a logical result because of the 3DCP process that filleted corners and creases. The 458 points with less than $12 \mathrm{~mm}$ deviations were visualized with diagrammatic 100 times scaled boxes at the location of the points of interest (Fig. $7 \mathrm{~d})$. As the deviation in neighboring areas was very similar, this led to the assumption that the elements still had a slightly offset position to the CAD model.

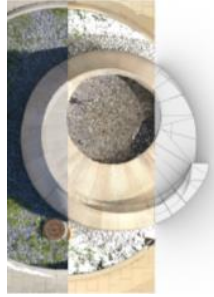

(a)

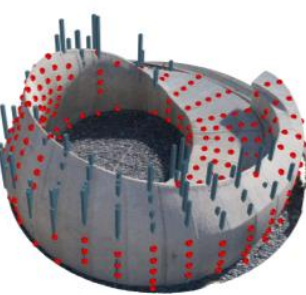

(b)

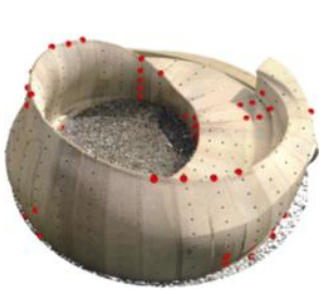

(c)

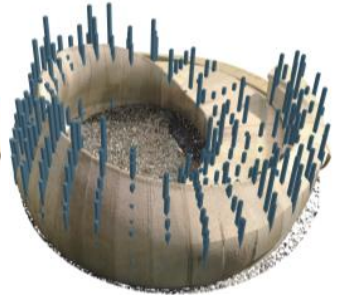

(d)

Fig. 7. Geometric inspection of an assembled structure: (a) overlay of photogrammetry, 3D laser scan and CAD model; (b) photogrammetry: points (marked in red) with deviations $>12 \mathrm{~mm}$, and points (marked in dark blue, values scaled by 100) with deviations < $12 \mathrm{~mm}$; (c) laser scanning: points (marked in red) with deviations $>12 \mathrm{~mm}$ standing out especially on corners and creases; (d) laser scanning: points (marked in dark blue, values scaled by 100) with deviations $<12 \mathrm{~mm}$.

\section{$4 \quad$ Results and discussion}

Table 1 presents the measurement system parameters from each case study. The structured light scanning method worked well at the scale explored, however the measurements were undertaken in a clean environment away from the manufacturing equipment. For measuring and verifying printed features, the method was robust. One 
observation was that the increased number of scans will increase the cloud point processing operations, which might affect the measurement of larger parts and also for a larger component both 3D laser scanning and photogrammetry, proved feasible to capture the large amount of data via multiple stations within acceptable time period. In the case of the assessment of the assembly, these processes also identified the accumulation effect of the manufacturing errors on the conformity of an assembly.

Table 1. Factors related to geometric inspections in the four case studies.

\begin{tabular}{|c|c|c|c|c|}
\hline $\begin{array}{l}\text { Quality control } \\
\text { action }\end{array}$ & $\begin{array}{l}\text { Machine } \\
\text { calibration }\end{array}$ & $\begin{array}{l}\text { Adaptive } \\
\text { feedback }\end{array}$ & $\begin{array}{l}\text { Postprocessing } \\
\text { assessment }\end{array}$ & $\begin{array}{l}\text { Assembly } \\
\text { verification }\end{array}$ \\
\hline $\begin{array}{l}\text { Inspection } \\
\text { technique }\end{array}$ & $\begin{array}{l}\text { Structured light } \\
\text { scanning }\end{array}$ & $\begin{array}{l}1 \mathrm{D} \text { laser } \\
\text { ranging }\end{array}$ & $\begin{array}{l}\text { 3D laser scanning/ } \\
\text { Photogrammetry }\end{array}$ & $\begin{array}{l}\text { 3D laser scanning / } \\
\text { Photogrammetry }\end{array}$ \\
\hline Object scale & $<0.5 \mathrm{~m}$ & Point & $<3.5 \mathrm{~m}$ & $<7.0 \mathrm{~m}$ \\
\hline Object surface state & Wet & Wet & Wet-Dry & Dry \\
\hline $\begin{array}{l}\text { Ambient lightning } \\
\text { condition }\end{array}$ & Indoor & Indoor & Indoor & Outdoor, sunny \\
\hline Measuring distance & $1.0-1.5 \mathrm{~m}$ & $\leq 0.2 \mathrm{~m}$ & $\geq 1.0 \mathrm{~m}$ & $2.0-3.0 \mathrm{~m}$ \\
\hline $\begin{array}{l}\text { Measuring (point } \\
\text { cloud) resolution }\end{array}$ & $0.3 \mathrm{~mm}$ & $1.0 \mathrm{~mm}$ & $>1.0 \mathrm{~mm}$ & $\begin{array}{l}2.0 \mathrm{~mm} \text { (laser } \\
\text { scanning) / } 4.0 \mathrm{~mm} \\
\text { (photogrammetry) }\end{array}$ \\
\hline Time consumption & $\begin{array}{l}\text { For an inspection } \\
\text { lot: } \\
15 \text { - } 20 \text { min for data } \\
\text { acquisition; } 2 \text { - } 4 \mathrm{hrs} \\
\text { for data processing }\end{array}$ & Real-time & $\begin{array}{l}30-60 \mathrm{~min} \text { for data } \\
\text { acquisition; } 2-5 \mathrm{hrs} \\
\text { for data processing }\end{array}$ & $\begin{array}{l}60 \text { min for data } \\
\text { acquisition; } 3 \text { days for } \\
\text { data processing }\end{array}$ \\
\hline $\begin{array}{l}\text { Cost of } \\
\text { measurement } \\
\text { equipment }\end{array}$ & $3-6 \mathrm{k} €$ & $<0.2 \mathrm{k} €$ & $\begin{array}{l}100 \mathrm{k} € \text { (laser scanning) } \\
\text { / } 5 \mathrm{k} € \\
\text { (photogrammetry) }\end{array}$ & $\begin{array}{l}\text { 50k } € \text { (laser scanning) } \\
/ 7 \mathrm{k} € \text { (drone setup + } \\
\text { software) }\end{array}$ \\
\hline
\end{tabular}

The 1D height measurement used for z-height correction on-the-fly was also promising. Key here is the speed at which the measurements can be processed into machine actions. With only linear distance measurements, this proved to be quite achievable. The method could be developed into 3D surface measurements to achieve 3D adaptive control for more complex applications of 3D curved geometries, which would then increase the required computational capacity.

Overall, the common technical challenges of different stage geometric inspection are time consumption (related to both data processing method and computational capacity), accessibility (inside of the structure), and ambient conditions (dirt, light, working space, etc). Since 3DCP is usually used for creating bespoke one-off large-scale components and structures, it's critical that the printing parts are right-first-time, which can be achieved through material and process control. Geometrical measurement is a critical part of this process for establishing and checking machine precision, correcting the 
uncontrollable aspects of the process and for verifying form, either for a secondary process, to establish whether it is to specification or to determine the as built case.

It is likely that, rather than the traditional quality control based on random sampling parts, the bespoke nature of the components manufactured with 3DCP combined with less predictable process factors, is likely to lead to individual part verification. The automation of these quality control procedures throughout machine setup, printing and post-printing are somewhat inevitable, at least until 3DCP processes are demonstrated to be under control such that the uncertainties on geometric tolerance become insignificant.

\section{$5 \quad$ Conclusions and outlook}

Additive Manufacturing with concrete offers more freedom in design and this has been demonstrated to lead to the manufacture of more bespoke complex geometries. 3DCP processes are currently not fully predictable because of a combination of material, environmental and process variables that are difficult to determine, isolate and mitigate the effects. The result is that the success of a print in terms of the geometrical conformance to the design drawing needs to be verified at every build.

Equally, it is likely that corrective action will be needed during manufacture to ensure a successful build, i.e. prevent collapse. Additional post-processing is will be important for many practical applications and so verifying the base print prior to the application of a more controllable second process is likely to become routine as a consequence. The expectation coming from this work is that more systematic use of measurement in the 3DCP manufacturing process will be a cornerstone of future systems.

Beyond pure quality control, digital data acquisition enables the creation of extensive databases in which production parameters such as nozzle size, feed rate, material, temperature and geometry etc. are recorded and correlated with the print result. With the participation of a larger research community in feeding such a database, it becomes increasingly possible through the use of sophisticated techniques such as artificial intelligence to make precise predictions about the future print results and potentially to make suggestions for optimized path planning and automated adjustment of the production parameters.

\section{Acknowledgements}

The case study in Section 3.1 was supported by: the UK Industrial Strategy Challenge Fund: Transforming Construction initiative (EPSRC grant number EP/S031405/1) and EPSRC Grant number EP/P031420/1.

The case study in Section 3.2 was part of a research project co-funded by a partner group of enterprises and associations, that consisted of (alphabetical order) Ballast Nedam, BAM Infraconsult bv, Bekaert, Concrete Valley, CRH, Cybe, Saint-Gobain 
Weber Beamix, SGS Intron, SKKB, Van Wijnen, Verhoeven Timmerfabriek, and Witteveen+Bos. Their support is gratefully acknowledged.

The case study in Section 3.3 was funded through the lower Soaxony Ministry of Science and Culture and the Lower Saxony Technical Universities (NTH). The Digitial Building Fabricaion Laboratory was funded through the German Research Foundation (DFG). The Junior Professorship for Digital Building Fabrication is funded by the Gerhard and Karin Matthäi Stiftung. The measurements were carried out as preliminary studies within the framework of TRR 277 "Additive Manufacturing in Construction".

\section{References}

1. Eagan, J.L.: Rethinking construction: The report of the Construction Task Force. Department of the Environment, Transport and the Regions, UK (1998). (Copy of report available on Constructing Excellence website: http://constructingexcellence.org.uk/wpcontent/uploads/2014/10/rethinking_construction_report.pdf, last accessed 2020/02/06.)

2. HM Government: Construction 2025: strategy, https://www.gov.uk/government/publications/construction-2025-strategy, last accessed 2020/02/06.

3. HM Government: Made Smarter Review, https://www.gov.uk/government/publications/made-smarter-review, last accessed 2020/02/06.

4. HM Government: Industrial Strategy: building a Britain fit for the future, https://www.gov.u $\mathrm{k} /$ government/publications/industrial-strategy-building-a-britain-fit-for-the-future, last acce ssed 2020/02/06.

5. Buswell, R. A., Leal de Silva, W. R., Bos, F. P., Schipper, R., Lowke, D., Hack, N., Kloft, H., Mechtcherine, V., Wangler, T., Roussel, N.: The RILEM process classification framework for defining and describing Digital Fabrication with Concrete. Cement and Concrete Research, (2020). To appear.

6. Marchon, D., Kawashima, S., Bessaies-Bey, H., Mantellato, S., Ng, S.: Hydration and rheology control of concrete for digital fabrication: Potential admixtures and cement chemistry. Cement and Concrete Research 112, 96-110 (2018).

7. Roussel, N.: Rheological requirements for printable concretes. Cement and Concrete Research 112, 76-85 (2018).

8. Reiter, L., Wangler, T., Roussel, N., Flatt, R.J.: The role of early age structural build-up in digital fabrication with concrete. Cement and Concrete Research 112, 86-95 (2018).

9. Asprone, D., Menna, C., Bos, F.P., Salet, T.A., Mata-Falcón, J., Kaufmann, W.: Rethinking reinforcement for digital fabrication with concrete. Cement and Concrete Research 112, 111121 (2018).

10. Buswell, R.A., Thorpe, A., Soar, R.C., Gibb, A.G.: Design data issues for the control of mega-scale rapid manufacturing. Figshare. Conference contribution. https://hdl.handle.net/2134/26938, last accessed 2020/02/06.

11. Buswell, R.A., Thorpe, A., Soar, R.C., Gibb, A.G.: Design, data and process issues for megascale rapid manufacturing machines used for construction. Automation in Construction 17(8), 923-929 (2008).

12. Lim, S., Buswell, R., Le, T., Wackrow, R., Austin, S.A., Gibb, A., Thorpe, T.: Development of a viable concrete printing process, (2011). 
13. Xu, J., Ding, L., Cai, L., Zhang, L., Luo, H., Qin, W.: Volume-forming 3D concrete printing using a variable-size square nozzle. Automation in Construction 104, 95-106 (2019).

14. Ketel, S., Falzone, G., Wang, B., Washburn, N., Sant, G.: A printability index for linking slurry rheology to the geometrical attributes of 3D-printed components. Cement and Concrete Composites 101, 32-43 (2019).

15. Chin, S., Kim, K., Kim, Y. S.: A process-based quality management information system. Automation in Construction 13(2), 241-259 (2004).

16. Fox, A.J., Cornell, H.A. eds.: Quality in the Constructed Project: Proceedings of the Workshop. Amer Society of Civil Engineers (1985).

17. Kavanagh, T.C., Müller, F., O'Brien, J.J.: Construction management: A professional approach. McGraw-Hill (1978).

18. Booker, J.D., Swift, K.G., Brown, N.J.: Designing for assembly quality: strategies, guidelines and techniques. Journal of Engineering design 16(3), 279-295 (2005).

19. Shafer, D.A.: Successful assembly automation: a development and implementation guide. Society of Manufacturing Engineers (1998).

20. Maboudi, M., Bánhid, D., Gerke, M.: INVESTIGATION OF GEOMETRIC PERFORMANCE OF AN INDOOR MOBILE MAPPING SYSTEM. International Archives of the Photogrammetry, Remote Sensing \& Spatial Information Sciences 42(2), (2018).

21. Wang, Q., Kim, M.K.: Applications of 3D point cloud data in the construction industry: A fifteen-year review from 2004 to 2018. Advanced Engineering Informatics 39, 306-319 (2019).

22. Kim, M.K., Thedja, J.P.P., Wang, Q.: Automated dimensional quality assessment for formwork and rebar of reinforced concrete components using 3D point cloud data. Automation in Construction 112, 103077 (2020).

23. Brilakis, I., Haas, C.T.M.: Infrastructure computer vision. Butterworth-Heinemann (2019). https://www.elsevier.com/books/infrastructure-computer-vision/brilakis/978-0-12-8155035, last accessed 2020/02/06.

24. Kim, M.K., Wang, Q., Li, H.: Non-contact sensing based geometric quality assessment of buildings and civil structures: A review. Automation in Construction 100, 163-179 (2019).

25. Labonnote, N., Rønnquist, A., Manum, B., Rüther, P.: Additive construction: State-of-theart, challenges and opportunities. Automation in Construction 72, 347-366 (2019).

26. Ahn, D., Kweon, J.H., Kwon, S., Song, J., Lee, S.: Representation of surface roughness in fused deposition modeling. Journal of Materials Processing Technology 209 (15-16), 55935600 (2009).

27. Buswell, R.A., de Silva, W.L., Jones, S.Z., Dirrenberger, J.: 3D printing using concrete extrusion: A roadmap for research. Cement and Concrete Research 112, 37-49 (2018).

28. Neudecker, S., Bruns, C., Gerbers, R., Heyn, J., Dietrich, F., Dröder, K., Raatz, A., Kloft, H.: A new robotic spray technology for generative manufacturing of complex concrete structures without formwork. Procedia CIRP 43, 333-338 (2016).

29. Popescu, C., Täljsten, B., Blanksvärd, T., Elfgren, L.: 3D reconstruction of existing concrete bridges using optical methods. Structure and Infrastructure Engineering 15(7), 912-924 (2016).

30. Omar, T., Nehdi, M.L.: Data acquisition technologies for construction progress tracking. Automation in Construction 70, 143-155 (2016).

31. Akinci, B., Boukamp, F., Gordon, C., Huber, D., Lyons, C., Park, K.: A formalism for utilization of sensor systems and integrated project models for active construction quality control. Automation in construction 15(2), 124-138 (2006). 
32. Gordon, S.J., Lichti, D.D.: Modeling terrestrial laser scanner data for precise structural deformation measurement. Journal of surveying engineering 133(2), 72-80 (2007).

33. Bosché, F.: Automated recognition of 3D CAD model objects in laser scans and calculation of as-built dimensions for dimensional compliance control in construction. Advanced engineering informatics 24(1), 107-118 (2010).

34. Kim, M.: Noncontact Quality Assessment of Precast Concrete Elements using 3D Laser Scanning and Building Information Modeling. Doctoral thesis (2015). https://lbezone.ust.hk/pdfviewer/web/viewer.html?file $=a H R O c H M 6 L y 9 s Y m V 6 b 25 l \mathrm{LnVZdC5}$ oay9vYmovMS9vL2IxNDUwNzE5L2IxNDUwNzE5LnBkZg==\#page=1, last accessed 2020/02/06.

35. Golparvar-Fard, M., Pena-Mora, F., Savarese, S.: Automated progress monitoring using unordered daily construction photographs and IFC-based building information models. Journal of Computing in Civil Engineering 29(1), 04014025 (2015).

36. Braun, A., Tuttas, S., Stilla, U., Borrmann, A.: Process-and computer vision-based detection of as-built components on construction sites. In: ISARC. Proceedings of the International Symposium on Automation and Robotics in Construction, vol. 35, pp. 1-7. IAARC Publications (2018).

37. Hamledari, H., McCabe, B., Davari, S.: Automated computer vision-based detection of components of under-construction indoor partitions. Automation in Construction 74, 78-94 (2017).

38. Besl, P.J., McKay, N.D.: Method for registration of 3-D shapes. In: Sensor fusion IV: control paradigms and data structures, vol. 1611, pp. 586-606. International Society for Optics and Photonics (1992).

39. Xu, J., Buswell, R.A., Kinnell, P., Biro, I., Hodgson, J., Konstantinidis, N., Ding, L.: Inspecting manufacturing precision of $3 \mathrm{D}$ printed concrete parts based on geometric dimensioning and tolerancing. Automation in Construction (accepted on 2020/04/16).

40. Cloudcompare.org: CloudCompare - 3D point cloud and mesh processing software Open Source Project, https://www.danielgm.net/cc/, last accessed 2020/02/06.

41. Lim, S., Buswell, R.A., Valentine, P.J., Piker, D., Austin, S.A., De Kestelier, X.: Modelling curved-layered printing paths for fabricating large-scale construction components. Additive Manufacturing 12, 216-230 (2016).

42. Wolfs, R.J., Bos, F.P., van Strien, E.C., Salet, T.A.: A real-time height measurement and feedback system for 3D concrete printing. In: High Tech Concrete: Where Technology and Engineering Meet - Proceedings of the 2017 fib Symposium, pp. 2474-2483. Springer, Cham (2018).

43. Lindemann, H., Gerbers, R., Ibrahim, S., Dietrich, F., Herrmann, E., Dröder, K., Raatz, A., Kloft, H.: Development of a shotcrete 3D-printing (SC3DP) technology for additive manufacturing of reinforced freeform concrete structures. In: RILEM International Conference on Concrete and Digital Fabrication, pp. 287-298. Springer, Cham (2018).

44. Grasser, G., Pammer, L., Köll, H., Werner, E., Bos, F.P.: Complex architecture in printed concrete: the case of the Innsbruck University 350th anniversary pavilion Cohesion. In: Proceedings of Digital Concrete 2020, (2020). 